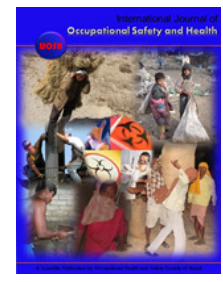

Available Online at http://nepjol.info/index.php/IJOSH

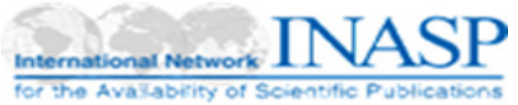

International Journal of Occupational Safety and Health, Vol 2. No 1 (2012) 2- 6

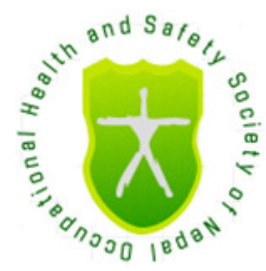

Review

\title{
Mental Health at Work Place
}

\author{
Susmita Halder', Akash Kumar Mahato
}

'Department of Psychology, Manipal College of Medical Sciences, Pokhara, Nepal, ${ }^{2}$ Consultant Clinical Psychologist, Kolkata

\begin{abstract}
:
Mental health denotes a symptom free mind and fair level of emotional well being. Be it home or workplace; mental health of an individual is subjected to environmental stressors that may reduce one's state of well being. The workplace in particular can be a very tiring environment for anyone. The stress of long working hours, ever increasing targets, managing coworkers and subordinates can take a toll on a persons mind and prove very toxic to one's mental and physical health in long run. It is difficult for persons with full blown mental illness to continue at work; but it generally takes a gradual course, before an individual shows full blown symptoms of a particular illness. Thus it becomes necessary to constantly check mental health and stress level of workers. The article discusses mental health, particularly in work place occupational stress and the related issues.
\end{abstract}

Key Words: Mental health, work place, occupational stress

The world Health Organization defines health as "A state of complete physical, mental and social well-being, and not merely the absence of disease or infirmity". It further defines mental health in a more elaborate way as "a state of well-being in which the individual realizes his or her own abilities, can cope with the normal stresses of life, can work productively and fruitfully, and is able to make a contribution to his or her community" [1]. While dealing with daily normal stresses of life is required from a healthy individual; the productivity and contribution to community are equally required for a healthy existence.

The workplace and the risks: It becomes important for an individual; rather say necessary to engage in some employment or other occupational activity for the very existence and well being of him and his family. However, every occupation comes with its own hazards. The physical hazards and the working environment can be a constant source of stress for the employees. Especially, extreme hot temperatures, high intensity sounds, poor or extreme light could be uncomfortable and trigger stress. While

Corresponding Author: Susmita Halder

Email: susmitahalder@gmail.com

(c) 2012 IJOSH All rights reserved. physical dangers at workplace are very apparent and can easily be taken care of using safety precautions, burnouts and stress are the other face of workplace hazards, which are not visible apparently and they take a gradual course and need careful monitoring and defences to deal with.

Every person before entering into a job has certain expectations from his own work and the organization, often setting his personal targets. Vice versa, the organization also has certain expectations from its employee. A certain motivation, feedback and reward fuel this interdependency. However, problem arises when there appears to be a misbalance between the two, and either of them starts expecting more from himself or the other without proper motivation, feedback, reward and resources. This is the stage when stress and burnout starts creeping in into the workers. While burnout is a shorter phase of exhaustion and related symptoms, stress is relatively a prolonged phase.

Stress: Theoretically stress has been put as a condition or feeling experienced, when a person perceives the demands of the environment exceeding his personal and social resources he is able to mobilize. Simply put, stress is wear and tear brought on by perceived threats by individual and his or her coping 
deficiencies. However, some researchers have described stress as a mediating hypothetical construct rather than an outcome measure of psychological ill health, differentiating stress from psychological ill health like depression and anxiety etc. [2]. But irrespective of these, it is widely been accepted that work related stress has undesirable impact on physical as well as mental health. It is important to note that unlike the popular notion, stress is neither a symptom, nor an event, or simply a problem. Rather it is a conglomerate of different situations, reactions, resulting conditions, and a process in continuum itself. Workplace related stressors can make a never ending list like,

- Increasing and difficult to meet targets of the organization,

- Multiple responsibilities,

- Long working hours,

- Lack of motivation and feedback,

- Poor pay and job satisfaction,

- The feeling of getting stuck,

- Sexual harassment or bullying,

- Unfavourable working conditions and

- Relations with co-workers as well as authority figures.

It can be said that these stressors do not cause stress themselves, rather how an individual perceives it and react to it, make them stressful. And it could be disastrous if not handled well. It could be a mistake if only excess workload is held culprit for all the occupational stress. Workers while entering an occupation may need to shift to a new place totally. This may require high adjustment in terms of food habits and living away from home and family. Workers may also require changing their sleeping habits, if put in variable shifts. The monotony of living alone in such unfavourable conditions may induce feelings of depression and anxiety in workers.

The Physiological component of stress: There is essentially a physiological process involved in stress. Though stress is said to be all in the mind, much of its manifestations are in terms of bodily responses. These bodily responses are an effort to meet the extra efforts on part of the individual to deal with the emergency situation like, increased heartbeat and blood pressure, expansion of blood vessels, reduction in non essential functions during the period, increase in muscle tone, enlargement of pupil, moistening of feet, change in activity levels of the immune system etc. Many of these symptoms are experienced by people when stress starts and they can be taken as indicators of stress arousal. Especially fast heartbeat, uneven breathing, dry mouth, restlessness, perspiration, fatigue, headache, backache, nervous stomach, reduced appetite are some of the very common indicators that people often ignore due to habituation. Frequent and repeated stress arousal can increase vulnerability to aggravate, and prolong a wide range of illness, like chronic headache, allergies, arthritis, chronic lung disease, hypertension, sleep disorders, ulcers etc. to name a few. On the other hand, excessive stress can interfere with the cognitive abilities of an individual to give his best at work. Exposure to stressful conditions in continuum is linked with minor lapses in memory and attention, inflexibility, changes in cognitive-perceptual function, creative thinking, decreased interpersonal sensitivity, emotion etc. Some individuals may adopt faulty health-related behaviours like smoking and alcohol consumption.

The Two-Way Impact: The effect of mental health on work and vice versa is a simple equation. An altered state of mental health can have disastrous impact on work, while unmanaged work conditions can alter ones mental well being.

The World Health Organization estimates that, as many as 200300 people of every 1,000 workers are likely to experience a mental health problem [3]. Prevalence of different mental disorders across the world varies in different populations. Generalized anxiety disorder for example has been reported in as low as $2.4 \%$ to a high $18.2 \%$ across different population in fourteen countries, while mood disorders including depression has been reported ranging from 0.8 to $9.6 \%$. [4]. Thus it can be understood that a significant working population have some symptoms of mental illness at any given time. However, it may not be concluded that work stress are the sole contributor to mental illness. But they do pose as a major risk. Studies suggest that reduced job security, longer fixed term working bonds; higher workload often without additional reward; high emotional demands, including bullying and violence; and a poor work-life balance are some of the emerging psychosocial risk factors behind poor mental health in the workplace [5]. While many workers manage their stress levels by effective coping and planning, some fail to do so and can develop symptoms enough to establish a clinical diagnosis.

Studies suggest mixed anxiety and depressive disorder as one of the most frequent problem reported in working people and more prevalent in women than men across all Standard Occupational Classifications [6]. On the contrast, severe form of mental 
illness like psychosis, cumulative with other diagnoses such as phobias and obsessive-compulsive disorders have resulted in an incidence of these conditions in only about $2 \%$ of the workforce.

As said earlier, altered state of mental health too have an impact on work productivity. While severe mental disorders cause direct loss to national economies tuning up to billion of dollars; less severe states like stress also cause financial loss to the economy of any country in terms of loss of productive hours, absenteeism, medical and care giving expenses. Recent studies have estimated the cost of depression alone for United states of America at US dollar 83.1 billion. Out of this absenteeism and impaired presenteeism accounted for about US dollar 51.5 billion [7]. Similar estimates for Korea has been put at US dollar 680 per month [8]. There may not be exact statistics of similar nature for countries worldwide, but the impact more or less remains the same.

Industries with high occupational stress: Every industry has its own stressors and hazards and it is difficult to say which industry has higher stress levels attached to its job nature. However, researchers may agree that the defense services worldwide are the most stressful industry. Especially those deployed in war zones, counter insurgency operations in hostile terrains are at higher risk of stress and burnout. The frequent change in postings, low leave sanctions adds to their frustration which occasionally results in suicidal acts. Soldiers have occasionally involved in acts of fragging too, when they seriously injure or kill themselves before killing or injuring one or many of their colleagues or seniors [9]. Various studies have frequently reported high rate of post traumatic stress and mental turmoil in soldiers especially when posted in highly hostile or inhospitable terrains $[10,11]$. Probably no other occupation carries as much risk as that of defence services, for unexpected exposure to trauma, which may come due to being evidence of killing hostile opponent, or the death of colleague in such acts.

Similarly, the Police services, Underground mine workers, Highway drivers, factory workers are some of the professionals who work in relatively more stressful conditions. Studies suggest that highway drivers, mineworkers often are under influence of substance while on work, which could be a risky affair. High-risk behaviour has been particularly reported among highway drivers [12 13], which increases the risk of sexually transmitted disease in them and subsequently into their spouse.

The issue of migrant and overseas workers: Migration itself has been identified as a potent stressor. Mental health of migrant
And overseas workers is constantly under threat, particularly in the initial phase of shifting. They may face a hostile local population because of their native affiliations and could be under risk of verbal or physical attacks. Several incidents of attack on migrant workers have been reported, like in India where Hindi speaking workers have been targeted in the north-eastern and southwestern states in recent past. On top of these, the family members of these workers too are in constant state of apprehension and worry. Studies suggest spouses of these workers having mixed anxiety and depressive symptoms as well as somatic symptoms. [14]

Managing stress at workplace: Stress at workplace can be effectively managed using certain principles and precautions. It could be a two way process calling for initiative from both the employee as well as employer. Managing stress level or to look after the mental health of its employees may not be in the standard charter of all organizations, especially in developing and third world countries. The most they could assist is by sanctioning medical leaves and paying the medical bills. However, a little effort from employers can be helpful in maintaining the mental health of its staff. It can be understood that stress level at work place could be arising chiefly from ever-increasing targets, faulty and inappropriate assignment of tasks, unfavourable work conditions and lack of reward on part of the employer. These could be handled effectively, if employers well identify the potentials of its employee. Although, all organizations may not afford for a psychological profile of its employees at the time of recruitment, mangers can definitely look into the strengths and weakness of its employee in due course. Additionally, employees can adapt a standard strategy to identify the potential hazards, which are most common to that particular industry and adapt appropriate controlling mechanisms for that. A special cell for this kind of assessment which can look after the efficacy of its measures and other alternatives could be a viable idea. It may also act as a forum where employees can address their concerns. An early tapping of these concerns from concerned authority can make a big impact and avert problems to rise in its intensity. Employers may also regularly check on the skill adequacy of its employees. Employees could be updated regularly on their skills through training sessions in their parent or some advance centres. This may help in boosting the confidence of employees and prepare them for the ever advancing and changing technologies.

On part of the employee, managing occupational stress can be seen as a continuing process which ultimately may become a habit. The best part of stress is that it triggers an automatic 
initiation of its own management. Thus it can be argued that stress bring along with it the coping too. However, all people may not be equally competent in managing stress owing to faulty coping and several other factors. The basic stress managing strategies may include the following:

The 1st step- Identifying the early signs: Owing to habituation, people often ignore the primary indicators of stress. It is important for all to realize stress and accepting when they are in stress. Owing to the 'not so significant' appearance of stress symptoms, people may not heed the warning considering it a temporary problem. Its only when, when some serious medical conditions crops or an existing one worsens, people look for consultation. So it is necessary to recognize the early signs of stress. Disturbed sleep and appetite, increased fatigue, irritability, lack of concentration etc. and other physical symptoms described earlier are the early indicators which one should not ignore. Accepting the situation can make the person more prepared and look for alternatives rather simply waiting for the adversities to pass on.

The 2nd step- Introspection: Many people are capable of doing the first step, i.e. recognizing themselves under stress, but see a dead end further, as they feel they are "doing their best". But one can have a self introspection and make certain changes accordingly that can help them to clear the 'blockade'. Important factors to look upon are:

Realistic and productive thinking: People often invite undue stress, owing to their faulty appraisals of the situations. An adverse situation is looked upon as the end of road or the worst thing that could happen to anyone. They look themselves as victims and blame everybody except themselves. However a small reality check can help reduce the severity of the conditions.

Effective Problem solving: There could be several ways to solve a problem (deal with a situation), and the strategies an individual adopts while solving these problems refer to problem solving. But in routine life, the difficulty lies in the fact that many people are unable to accept when things do not happen their way. In spite of other options being available, they are not explored simply because they may not look viable or interesting in the first instance. Thus it is a good idea to look for other options or plan if the original doesn't work. People try to do things in a conventional way, which may not be the right strategy always. One can plan his best strategy that suits at that particular period of time.
Assertive communication: Lack of proper assertiveness while communicating with others often present an unclear picture of an individual and his or her real intentions. This can make the person prone to exploitation, especially in work places. A worker may prone himself for extra unwanted work forwarded from his or her colleagues or authority. Thus a person need to be assertive, that is to honestly and effectively express one's thoughts, wants, and feelings but at the same time empathically recognizing and respecting the thoughts, wants and feelings of others. This can not be a one day task, but with practice is achievable. As an individual one should always remember that he or she

- Has the right to dignity and self- respect.

- Has the right to say NO

- Has the right to ask for help

- Has the right to be less than what others expect of you. At the same time it's a good idea to put oneself in other person's shoes. It helps to rationally analyse other's behaviour and avoid unnecessary unwanted altercations.

\section{The 3rd step- Adoption of supportive and palliative} measures: A healthy mind live in a healthy body is an old saying. One can not fight with adversities if he or she is not in good health. Even psychological defences seem to weaken in ill health. Thus, it is advisable to adopt a healthy life style. Practicing yoga, regular participation in sports, relaxation exercises and maintaining a healthy diet are some effective measures that can ward off stress in daily life.

Summary: Mental health of employees in any work settings is exposed to a number of risk factors, which could destabilise it. Apart from difficult working conditions, problems related to mental health may arise from unreasonable expectations and faulty strategies. Mental unwell being even if not amounts to serious mental illness, it is hazardous in terms of revenue loss, poor productivity and serious health issues for the employee. Managing occupational stress and mental health of its employees may not be a standard practise in developing countries but it could be a simple task if employees recognise it readily, introspect analytically, and use better problem solving with the aid of assertive communication and palliative measures. 


\section{Reference}

1. World Health Organization. www. who.int

2. Michie $S$ and Williams $S$. Reducing work related psychological ill health and sickness absence: a systematic literature review. Occup Environ Med. 2003, 60: 3-9. (2003)

3. World Health Organization. www. who.int/ topics/ mental_health

4. Demyttenaere K, Bruffaerts R, Posada-Villa J, et al. Prevalence, severity, and unmet need for treatment of mental disorders in the World Health Organization World Mental Health Surveys. JAMA 291. 2004, 21: 2581-90.

5. European Risk Observatory. Expert forecast on emerging psychosocial risks related to occupational safety and health. Bilbao: European Agency for Safety and Health at Work, 2007.

6. Stansfield SA, Head J, Rashul S, Singleton N and Lee A. Occupation and Mental Health: Secondary analysis of the ONS Psychiatric Morbidity Survey of Great Britain. London: HSE Books, 2003.

7. Greenberg PE, Kessler RC, Birnbaum HG, Leong SA, Lowe SW, Berglund PA, Corey-Lisle PK. The economic burden of depression in the United States: how did it change between 1990 and 2000? J Clin Psychiatry. 2003, 64 (12): 146 -75.

8. Lee YM. Loss of productivity due to depression among Korean employees. J Occup Health. 2010, 52 (6):389-94.

9. Times news network. (July 18 2010). www.timesofindia.com.

10. Chaudhury S, Goel S D, Singh H. Psychological effects of low intensity conflict (LIC) operations. Indian J Psychiatry. 2006, 48 (4): 223-231.

11. Tyler CS, Margaret AKR, Deborah LW, Donald JS, James FS, Donna KS. New onset and persistent symptoms of posttraumatic stress disorder self reported after deployment and combat exposures: prospective population based US military cohort study. British Med Jr. 2008, 336 (7640): 366-371.

12. Stratford D, Ellerbrock TV, Akins JK, Hall HL. Highway cowboys, old hands, and Christian truckers: risk behaviour for human immunodeficiency virus infection among long-haul truckers in Florida. Soc Sci Med. 2000, 50(5):737-49.

13. Pandey A, Benara SK, Roy N, Sahu D, Thomas M, Joshi DK, Sengupta U, Paranjape RS, Bhalla A, Prakash A, et al. Risk behaviour, sexually transmitted infections and HIV among long-distance truck drivers: a cross-sectional survey along national highways in India. AIDS. 2008, 22(5):81-90.

14. Zelkowitz P, Schinazi J, Katofsky L et al. Factors Associated with Depression in Pregnant Immigrant Women. Transcultural Psychiatry. 2004, 41(4): 445-464. 